\title{
Nociones generales sobre el fondo de ojo normal
}

\section{Doctor Alfoso Tribin Piedrahita}

Al iniciarse la publicación de le Revista Colomblana de Obstetricia y Ginecologia, recibi del Profesor Rsfael Ramirez Merchán la galante invitación de colaborar en ella. Fue así como en el primer número aparecí́ un artículo de gran interés para el obstetra, titulado Eclampsia y re tina.

Siempre he creido, como lo anota Ramond, al estudiar las parálisis oculares, que las diversas especializaciones tan necesarias para el progreso cientifico y para garantía del paciente, deben complementarse reciprocamente ya que el cuerpo humano es único y si bien, las enfermedades tienen en general predilección por órganos definidos, no es menos cierto que ellas, cualquiera que sea su localización, acarrean sintomatologia a distancia, la que en multitud de ocasiones nos lleva al diagnóstico positivo.

Al describir las complicaciones retinianas de la Eclampsia hice hincapié en la necesidad absoluta que tiese el médico, no importa su especialización, de familiarizarse con el empleo del oftalmoscopio y de conocer con alguna precisión los detalles del forido de ojo. En esta oportunldad trataré de describir el aspecto normal de este, utilizando la Oftalmoscopia directa.
Para el principiante es necesario verificar este examen con pupila dilatada, midriasis que se obtiene en forma satisfactoria con la Euftalmina del 3 al $5 \%, 0$ con la homatrop:na al $2 \%$. No es recomendable la atropina, pues además de paralizar la acomodación por un tiempo más o menos largo, es de peligro en personas de edad prẹdispuestas al giaucoma.

El examen de fondo de ojo debe practicarse en forma ordenada, obteniendo primero una visión de conjunto y luégo detallando con precisión cada uno de los elementos que lo constituyen.

Coloración. La retina, a excepción de la capa pigmentaria y le los va. sos, es transparente. Los rayos luminosos procedentes del oftalmoscopio, la straviesan, llegan a la cara interna de la esclerótica en donde se reflejan, y recorren en sentido inverso el trayecto inicial, para ser recibidos por el observador. Este recorrido hace que el examirador perciba el fondo de un color rojo mas o menos intenso, coloración que depende del liquido sanguineo coroidiano y de la mayor o menor concentración pigmentaria.

Es clásico dividir la coloración normal del fondo del ojo en cuatro tipes principsles. 
a) Rojo uniforme, pardo-rojizo y oro oscuro. Se presenta el primero en los morenos, el segundo en los morenos con tendencia al tipo negro y el tercero en los negros. La cantidad de pigmento retiniano estả generando uno u otro tipo y como se ve, la coloración del fondo ocular guarda relación con el color de la piel.

b) Fondo de ojo rosido. En este coso el pigmento está poco desarrollado pero no ausente. Este color se observa preferentemente on las personas rubias.

c) Fondo de ojo de los allinos. Aoui, el fondo es aún más claro que en el caso anterior; pueder percibirse porciones blancas o bles 20 amarillentas correspondientes is tejido sscleral. La capa pigmentaria está ausente.

d) Fondo ocular atigrado o en mosaico. Es de observación frecuente en la miopia. En este tipo el pigmento retiriano es escaso, siendo en cambio abundante el de la coroides. Por esto, se verán alternando porciones de color rojo o rosado, con zonas negras. Debe tenerse el cuidado de :1o confundir estas zonas pigmentaras con coroido retinitis que no cue no existen.

B). Vasos. Dos clases de vasos ueden observarse: los retinianos $\mathbf{y}$ os coroidianos. Su diferenciación es nuy importante pues debemos recoriar que los retinianos son siempre terminales y no se anastomosan.

Los vasos retinianos son más suerficiales, convergen hacia la paila, no forman plejos, son terminales no se anastomosan, presentan eflejos luminosos, sus contornos on más netos $y$ se dividen en forma dicotómica. Los vasos coroidianos son más profudos e imprecisos, generalmente de mayor volumen y presentan numerosas, irregulares y variadas redes anastomóticas.

C). Reflejos retinianos. En sujetos jóvenes el examen oftalmóscópico puede dificultarse debido a la aparición de reflejos luminosos localizados especialmente en la mácula y en los vasos, o sea en aquellas zonas en donde se encuentran depresiones retinianas. Se desplazan con los movimientos del oftalmoscopio y no tienen en este caso significación patológica.

Hechas estas consideraciones podemos entrar a analizar los diversos elementos del fondo ocular, empezando por la papila.

I-Papila. Corresponde a la entrada o "cabeza" del nervio óptico en el globo ocular. Tiene en general, una forma circular, pero ésta puede cambiar en oportunidades, variación que en la mayoría de las veces corresponde a un defecto de refracción.

Los autores norteamericanos la designan con el nombre de "disco", evitanco el error en que frecuentemente se cae al creer que, dada su denominación genérica de papila, se encontrará un elemento que hace mayor o menor saliencia dentro del globo.

Su tamaño a la oftalmoscopia directa es aproximadamente 10 a 15 veces mayor que su tamaño real, 10 que equivale a decir que al examen se vori de 2 centimetros de diámetro, siendo en verdad de uno y medio milímetros. Puede varin este tamaño con el estado de refraccion del ojo. 
viéndose mayor en el miope que en el hipermetro fuerte, cuando se utiliza, entiéndase bien, el método :irecto.

En cuanto al color es muy importante saberlo apreciar y distin. guir, para poder apreciar cambios papilares por pequeños que sean. Es costumbre dividir verticalmente la papila en dos mitades iguales, una externa o temporal y otra interna o nasal. La primera, contiene menos fibras nerviosas, menos vasos y su color será apenas rosado pálido. La segunda, más rica en fibras nerviosas, más intensamente vascularizada, aparece de un color rosado intenso. En el centro de la papila aparece frecuentemente una zona blanquecina, circular u ovalada, que corresponde a la ? nina cribosa, punto de entrada del nervio; en algunas oportunidades esta zona esta deprimida formando una excavación que es importante reconocer. En efecto, la excavación antes mencionada, es pequeña y no alcanza los bordes papilares. Recibe el nombre de "fisiológica", en oposición a la patológica, tipo glaucoma, en cuya formación participa todo el disco. En ocesiones en el fondo de la excavación fisiológica, pueden verse pequeños puntos grisáseos que corresponden a los orificios que en la lámina cribosa, dan paso a las fibras ópticas.

El disco óptico tiene bordes netos en la mayor parte de su extensión. Suele estar limitado por ris anillos. Uno blanco, interno, escleral o conjuntival, y uno pigmentado, externo, formado por acumulación die pigmanto retiniano

Los vasos paplures proc ien en general de la arteria central de la retina. Esta penetra al nervio antes de llegar al globo ocular y luégo es apreciada en el interior del ojo, apareciendo, en la mayoría de los casos, en el centro de la papila en donde se dividirá en sus ramas terminales. Sinembargo, esta división sufre variaciones y el aspecto oftalmoscópico será diferente en cada caso, ya que en la papila pueden aparecer o los vasos terminales por división prematura, o el tronco en el instante mismo en que se divide o un trayecto del tronco principal con bifurcación posterior. En todo caso conviene saber que las ramas procedentes de la arteris central y que después recorren la retina, son dos, una superior y otra inferior, las que a su vez se dividen en una rama interna y otra externa o temporal, asegurando asi la irrigación de toda la retina. Una vena acompaña a cada arteria, haciendo, a la inversa, un recorrido similar.

En la papila, independientemente de la arteria central, se pueden ver una o más arterias que se dirigen hacia la mácula y que ascguran una doble irrigación retiniana en este sector. Son las arterias Cilio-retinianas, cuya presencia es muy favorable en caso de obstrucción de los vasos principales

Las arterias retinianas se diferencian de las venas, por los siguientes caracteres: Son más delgadas y rectilineas; tienen un color rojo brillante, no oscuro como las venas; exhiben un reflejo luminoso central mís marcado que en las venas.

Tanto las arterias como las venas pueden presentar pulsación espontánea En las primeras este hallazgo es patológico finsuficiencia ártica, 
glaucoma, etc.). En las segundas no tiene, generalmente, significación especial.

II-Mácula. Para examinarla, conviene hacer mirar al paciente la fuente luminosa que emana del oftalmoscopio. En esta forma aparece una porción de la retina con caracteres propios. Situada exactamente en el polo posterior del ojo, hacia afuera de la papila, exhibe un gran número de casos, un color más subido que el de las porciones vecinas.
Puede estar rodeada de uno o más anillos brillantes, parciales o completos, poco marcados en los viejos. Hay que observar muy bien la mácula, cuando ella es francamente visible pues hay ocasiones en que no lo es, para evitar el error de confundirla con un punto hemorrágico.

Al descubrir el aspecto en general del fondo del ojo, vimos el aspecto general de la coroides y retina, de manera que no se debe insistir sobre estas dos capas endoculates.

\section{Las manifestaciones vásc lo-renales de la gestación}

H. Vermelin y M. Ribon.

Gynecologie et Obstèt que. Paris. No 2. 1949.

En un extenso estudio sobre las manifestaciones vásculorenales de la zstación, los autores actualizan las Hoas atunederas a tan apasionante pitulo de la clínica obsiétrica. Con 6. elegancia, claridad y precisión, ya 1 verbiales en los médicos de $I$ ancia, hacen un recuento $y$ un it alisis de la albuminuria que apare en algunas embarazadas, estabeciendo la distinción entre la albuminuria sintomática sin lesión renal y la conexa a una nefritis, sea ante$r$ r al embarazo, sea adguirida du$r$ trte la evolución de este. Por otra pute, recalcan sobre la albumintri. expresión de una "enfermedad gravidica verdadera", capaz de exj ctarse clinicamente por toda una gama de trastornos de gravedad creciente, desde la albuminuria aislada hasta los espectaculares sindromes convulsivos y hemorragicus.

En el estudio de Vermelin y Ribon se habla del disfucionamiento hipófiso-diecefálico como génesis de la "enfermedad gravidica" al cual responde con gran sensibilidad el riñón por ser "el espejo del equilibrio gravidico"; y en cuanto a la terapéutica arotan el régimen higiénico-dietético, las dosis moderadas de extracto tiroidiano, el sulfato de ragresia en inyección endovenosa $y$ desechan por peligrosos, en las formas paroxisticas, la sangria y los barbituricos. 